\title{
Sujeitos invisíveis e acessos possíveis: cuidado à saúde bucal de pessoas com fenda orofacial e expressões
}

\author{
Invisible people and possible accesses: the oral health care of the \\ people with orofacial cleft and expressions
}

Priscila Figueiredo Cruz Ramos ${ }^{\mathbf{1}}$, Fábio Solon Tajra²

DOI: $10.1590 / 0103-1104202012411$

RESUMO O objetivo deste estudo consiste em compreender o cuidado à saúde bucal de pessoas com fenda orofacial e suas expressões. Esta pesquisa teve a história de vida como recurso metodológico. Analisaram-se as narrativas de quatro mulheres com idades entre 19 e 28 anos, moradoras da zona urbana de um município do Nordeste brasileiro. Foram estruturados quatro encontros, gravados e transcritos, em que vivenciou-se a construção de uma identidade e formação do vínculo, resgate das redes sociais e comunitárias de apoio, caminhos percorridos nos serviços de saúde e a percepção sobre os serviços. A análise dos dados foi inspirada na abordagem hermenêutica de P. Ricoeur. Identificaram-se quatro unidades de sentido: Ser-fissurado?; Rede de cuidados; Fluxos assistenciais em saúde bucal para pessoas com fenda orofacial e suas expressões; e Percepção sobre os serviços de saúde. Concluiu-se que há uma rede fragmentada quanto ao cuidado à saúde bucal, com falhas na comunicação, articulação e integração dos serviços de saúde, pouco envolvimento e apropriação dos casos pelas equipes de atenção básica, com importantes repercussões dos estigmas sociais sobre o paciente. Assim, estratégias para o aprimoramento das relações, bem como articulação e integração entre os serviços devem ser desenvolvidas na tentativa de superar tais problemas.

PALAVRAS-CHAVE Acesso aos cuidados de saúde. Saúde bucal. Fissura labial. Fissura palatina. Pesquisa qualitativa.

1 Universidade Estadual do Piauí (Uespi), Residência Multiprofissional em Saúde da Família e Comunidade Teresina (PI), Brasil.

2 Universidade Federal do Piauí (UFPI), Centro de

Ciências da Saúde (CCS) Teresina (PI), Brasil. fstajra@hotmail.com
ABSTRACT The objective of this study was to understand the oral health care of people with orofacial cleft and their expressions. This research had the history of life as a methodological resource. It was analyzed the narratives of four women aged between 19 and 28 years, living in the urban area of a Brazilian northeast municipality. Four meetings were structured, recorded and transcribed, in which we experienced the construction of an identity and formation of a bond, rescue of social and community support networks, paths taken in health services and perception on services. The analysis of the data was inspired by the hermeneutic approach of P. Ricoeur. Four sense units were identified: Be a person with orofacial cleft?; Health care network; Oral health care flows for people with orofacial clefts and their expressions; and, Perception about health services. It was concluded that there is a fragmented oral health care network, with poor communication, articulation and integration of health services, low involvement and appropriation of cases by primary care teams, with important repercussions of social stigmas on the patient. Thus, strategies for improving relations, as well as articulation and integration among services should be developed in an attempt to overcome such problems.

KEYWORDS Health Services Accessibility. Oral Health. Cleft lip. Cleft palate. Qualitative research. 


\section{Introdução}

O cuidado à saúde deve ser oportunizado após o reconhecimento das necessidades, demandas e representações da população. Exige a atuação, a articulação e a integração de diversos sujeitos e setores na tentativa de se construir uma rede, tendo em vista a integralidade'. Aqui, é importante salientar que o propósito de cuidado vai além da questão técnica. Inclui a atenção e a assistência à saúde e faz referência ao empoderamento dos sujeitos que operam para a transformação de suas práticas².

A organização e o funcionamento das ações e dos serviços em Redes de Atenção à Saúde (RAS) fazem parte dessa construção. Constituem elementos de reestruturação, mantendo a coerência com os princípios e as diretrizes do Sistema Único de Saúde (SUS) ${ }^{3}$. Esse é um dos aspectos da atual política de saúde brasileira, formalizado por meio da Portaria $n^{\circ} 4.279 / 2010$ e do Decreto $n^{0} 7.508 / 2011^{4,5}$.

$O$ trabalho em rede exige a participação de uma equipe multiprofissional e uma atuação interdisciplinar, aliada a um modelo de atuação intersetorial5,6. Esse é um desafio a ser superado pelas diversas categorias profissionais, e a odontologia é uma delas ${ }^{6}$.

A odontologia tem uma trajetória singular na história das políticas públicas brasileiras. A sua inserção no modelo de atenção orientado pela Atenção Primária à Saúde (APS) e com enfoque nas famílias e comunidades se deu após sete anos de implantação do Programa Saúde da Família 7,8. A partir das Conferências de Saúde Bucal e da formalização da política nacional, intitulada Brasil Sorridente, percebe-se uma transformação no trabalho em saúde e a incorporação de aspectos mais abrangentes na saúde bucal das pessoas e comunidades ${ }^{6}$.

A Política Nacional de Saúde Bucal (PNSB) propôs níveis de atenção com enfoque na humanização do trabalho e na integralidade do cuidado. Isso foi possível por meio da construção de linhas de cuidado, as quais consistiram na concretização das ações e dos serviços da RAS. Entre as linhas de cuidado, podem-se citar: grupos etários, saúde do trabalhador, pessoas com deficiência, pessoas com doenças crônicas e saúde da mulher ${ }^{8}$.

No Brasil, uma das redes temáticas de maior relevância tem sido a Rede de Atenção à Saúde Materno-Infantil. Isso se deve ao movimento disparado no âmbito mundial e esteve contido nos objetivos do milênio da Organização Mundial da Saúde ${ }^{9}$. A Rede Cegonha, instituída por meio da Portaria de ${ }^{0} 1.459 / 2011$, é resultante desse movimento e está consolidada no País ${ }^{10}$.

A Rede de Cuidados à Pessoa com Deficiência (RCPCD), instituída no âmbito do SUS por meio da Portaria n ${ }^{\circ}$ 793/2012, também apresentou destaque no Brasil. Foi implantada com a intenção de ampliar o acesso e qualificar o atendimento às Pessoa com Deficiência (PcD) no SUS, assim como de promover a sua vinculação e de suas famílias aos pontos de atenção e garantir a articulação e a integração dos serviços em redes. Aqui, a saúde bucal se mostrou transversal a todos os seus componentes, seja nas Unidades Básicas de Saúde (UBS), nos Centros de Especialidades Odontológicas (CEO) ou nas unidades hospitalares e em todos os níveis de atençãa ${ }^{11,12}$.

O movimento em prol do cuidado à saúde bucal de PcD teve outro marco histórico, ainda em 1994, por meio do Portaria SAS/MS n ${ }^{\circ}$ $62^{13}$. Naquela ocasião, foram estabelecidas normas para o cadastramento de hospitais que realizassem procedimentos integrados para reabilitação estético-funcional dos portadores de má-formação lábio-palatal para o SUS, bem como elencados aspectos da estrutura física, dos equipamentos e categorias profissionais que, aqui, seriam indispensáveis. Em se tratando dos procedimentos e do financiamento para o serviço, outras bases normativas foram publicadas, a saber: Portaria SAS/MS n ${ }^{0} 718$, de 20 de dezembro de 2010, e Portaria GM/ $\mathrm{MS} \mathrm{n}^{\circ} 2.867$, de 27 de novembro de 2008 ${ }^{13,14}$.

No Brasil, somente 28 hospitais foram credenciados. Um deles encontra-se em Teresina, Piauí15. Contudo, sabe-se que a unidade hospitalar não dá conta de todas as necessidades e demandas relacionadas ao cuidado à saúde de PcD. É importante investir no fortalecimento de outros pontos de atenção à saúde, assim como 
no desenvolvimento do potencial humano, das relações e da dinâmica para o trabalho em rede. Após vivenciar o processo de territorialização e planejamento em saúde durante a Residência Multiprofissional em Saúde da Família e Comunidade, foram observados casos de má-formação congênita relacionados ao processo de desenvolvimento orofacial. Um deles envolvia uma gestante que expressava essa situação e, na oportunidade do contato, era conhecedora desse diagnóstico também para a sua criança. Isso gerou uma reflexão de como o cuidado estava sendo conduzido para a mulher e de que forma estava sendo preparada para cuidar do seu bebê.

Diante disso, o questionamento que movimentou este estudo surgiu quanto ao cuidado à saúde bucal e à construção de redes. Assim, objetiva-se compreender o cuidado à saúde bucal de pessoas com fenda orofacial e suas expressões.

\section{Material e métodos}

Foi realizada pesquisa qualitativa, em que a história de vida foi utilizada como recurso metodológico ${ }^{\mathbf{1 6}, 17}$. Trata-se da história contada por quem a vivenciou, com a finalidade de apreender e compreender a vida conforme ela é relatada e interpretada ${ }^{\mathbf{1 7}}$. A partir disso, foi possível caracterizar a prática social de um grupo de pessoas acerca do cuidado à saúde bucal com resgate dos seus valores, definições e atitudes.

A análise dos dados foi desenvolvida a partir do referencial teórico da hermenêutica de Paul Ricoeur ${ }^{18}$. A Teoria de Ricoeur está fundamentada em três níveis: o da vida cotidiana ou do vivido, o da vida científica e o nível propriamente reflexivo, contemplando a fenomenologia, a ciência e a filosofia da linguagem, respectivamente19. Assim, toda a produção de dados diz respeito a questões singulares.

Neste estudo, foram considerados os sentidos e as unidades de significado de cada uma das narrativas produzidas, obtidos após a imersão em três fases: leitura inicial do texto, leitura crítica e apropriação. Trata-se aqui de uma possível compreensão sobre essa temática a partir desses achados de pesquisa. Faz-se referência a contextos e cenários específicos. Assim, é possível que outras compreensões possam ser geradas a partir de relatos de vida diversos ${ }^{18,19}$.

A pesquisa foi realizada com mulheres de um dos bairros da zona leste/sudeste do município de Teresina (PI). Participaram da pesquisa mulheres nas idades compreendidas de 19 a 28 anos, com fenda orofacial e suas expressões, ou mães de crianças com essa condição. $\mathrm{O}$ diagnóstico clínico específico da fenda orofacial (se fenda labial exclusiva, por exemplo) não foi levado em consideração. Para este estudo, foi considerado o diagnóstico ao nascer com a fenda labial e/ou palatina (associadas ou não).

Todos os sujeitos que participaram do estudo foram selecionados a partir do processo de territorialização. O contato com as mulheres para participação na pesquisa foi feito pelo pesquisador principal.

As entrevistas foram estruturadas em quatro encontros com cada participante, a saber:

i. Primeiro encontro: apresentação e aproximação, além do reconhecimento das necessidades de saúde e cuidado. O recurso utilizado foi um autorretrato construído por meio de desenho.

ii. Segundo encontro: construção do ecomapa, reconhecimento da história de cuidado dos sujeitos e suas relações. Pergunta disparadora: 'quando o assunto é cuidado à saúde, que sujeitos e equipamentos sociais e de saúde compõem sua rede?'.

iii. Terceiro encontro: reconhecimento das necessidades, demandas e representações das pessoas com fenda orofacial e suas expressões, com ênfase na saúde bucal, além da identificação do itinerário para a materialização do cuidado.

iv. Quarto encontro: análise da percepção dos serviços de saúde, além das possibilidades de aperfeiçoamento e melhoria da rede. 
Os encontros aconteceram em uma sala da Unidade Básica de Saúde (UBS) ou na residência da participante, conforme sua escolha. Cada um desses encontros teve tempo médio de 60 minutos; foi gravado; e, posteriormente, transcrito para análise.

O projeto de pesquisa foi aprovado pelo Comitê de Ética da Universidade Estadual do Piauí, sob o número 2.059.339. Os nomes das participantes da pesquisa, aqui apresentados, são fictícios.

\section{Resultados e discussão}

Analisaram-se as narrativas de 4 mulheres entre um universo de 11 casos identificados. Destes, 3 eram menores de 18 anos, 1 havia mudado de bairro durante a pesquisa e outras 3 se recusaram a participar. As 4 mulheres que fizeram parte deste estudo apresentaram histórias singulares, que se diferenciam desde o diagnóstico até $\mathrm{o}$ acesso à rede. Vale ressaltar que as narrativas apresentadas dizem respeito a trajetórias e acontecimentos que atravessam ciclos de vida diferentes e, por isso, resgatam necessidades, demandas e representações diversas. Isso foi levado em consideração na análise.
Construiu-se uma breve caracterização dessas histórias e, em especial, as intercorrências do itinerário terapêutico. A saber:

A história de Frida: "na escola, perguntavam se eu era de outro país ou era de outro mundo".

Frida, teresinense, 26 anos, casada, tinha uma filha também com o diagnóstico de fenda orofacial obtido ainda durante a gestação. Carregava um grande peso consigo, já que atribui a separação de seus pais ao diagnóstico. Sua mãe, em uma 'vida Severina', teve que priorizar a alimentação da família em detrimento de sua cirurgia. Com a demora no acesso à cirurgia, Frida foi vítima do estigma social durante sua infância. Ela se deparou com um meio social que a isolava e, por isso, perdeu um ano escolar. No início da adolescência, teve acesso ao procedimento cirúrgico no palato. Assim que fez a cirurgia, relatou que passou três meses sem falar, porque estranhou sua própria voz. Buscou meios diversos de superação. Além de forte religiosidade, contou com uma rede de apoio familiar e profissional. De sua rede assistencial, destacou os profissionais da psicologia e da fonoaudiologia. Depois de tudo que tinha passado, Frida percebia que a sua relação com a rede de apoio familiar, composta por sua mãe e sua irmã, é um ponto forte na sua vida (figura 1).

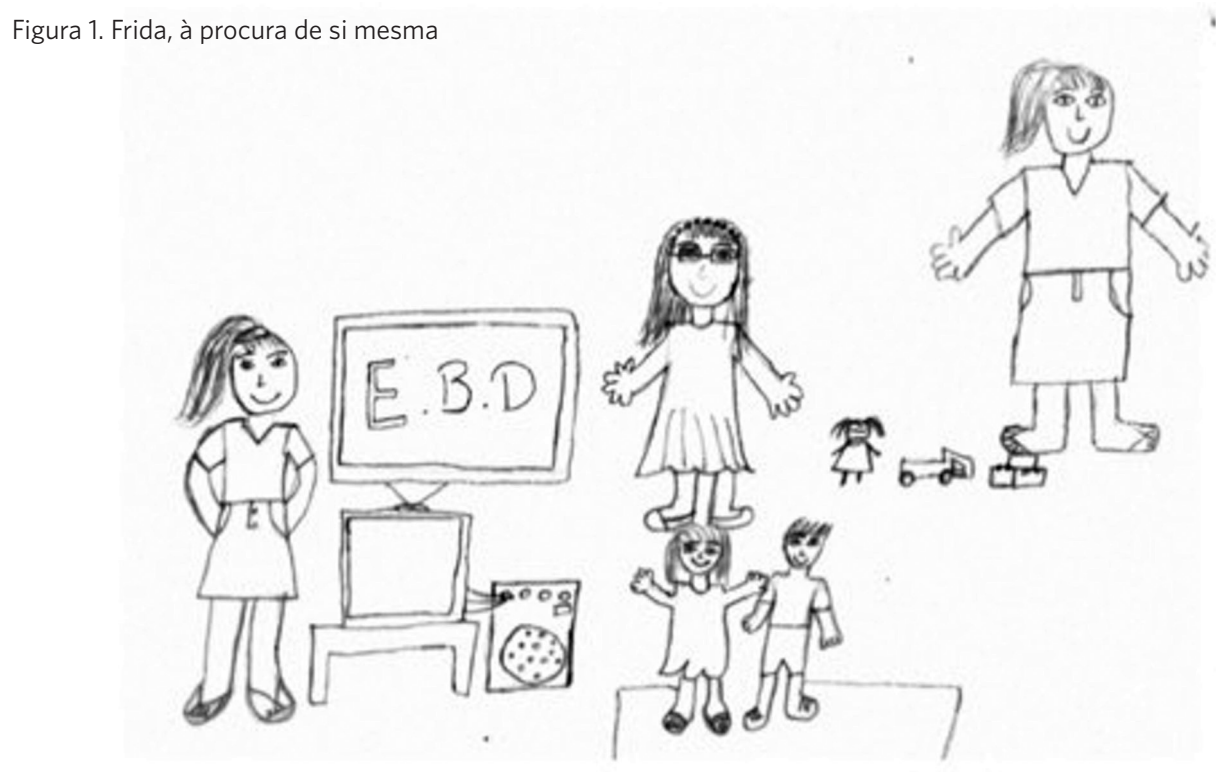


O que Tarsila tem para contar: "o hospital é a minha segunda casa".

Tarsila, teresinense, 20 anos, casada, estava gestante e foi diagnosticada assim que nasceu com fenda orofacial, que se estendia do lábio ao palato. Relatou ter passado por dificuldades, pois não conseguia segurar o alimento na boca. Somado a isso Tarsila tinha muita ânsia de vômito e queixava-se de sangramentos frequentes. Foi amparada pelos pais, que sofriam com o seu estado de saúde e a acompanhavam nas suas peregrinações pelos hospitais do município.
Tinha o hospital como uma segunda casa, pois havia permanecido lá por muito tempo. Sentiase muito grata por todo tratamento no hospital, porque foi lá que realizou o tratamento clínico e cirúrgico para o fechamento da fenda. Além da equipe médica e odontológica, contou com o cuidado do fonoaudiólogo. Tarsila era grata ao cuidado e à preocupação dos seus pais, que significavam um porto seguro. Também demonstrou ansiedade e apreensão, pois estava gestante e não sabia, ainda, se o seu filho apresentava o mesmo defeito congênito (figura 2).

Figura 2. Tarsila, por ela mesma
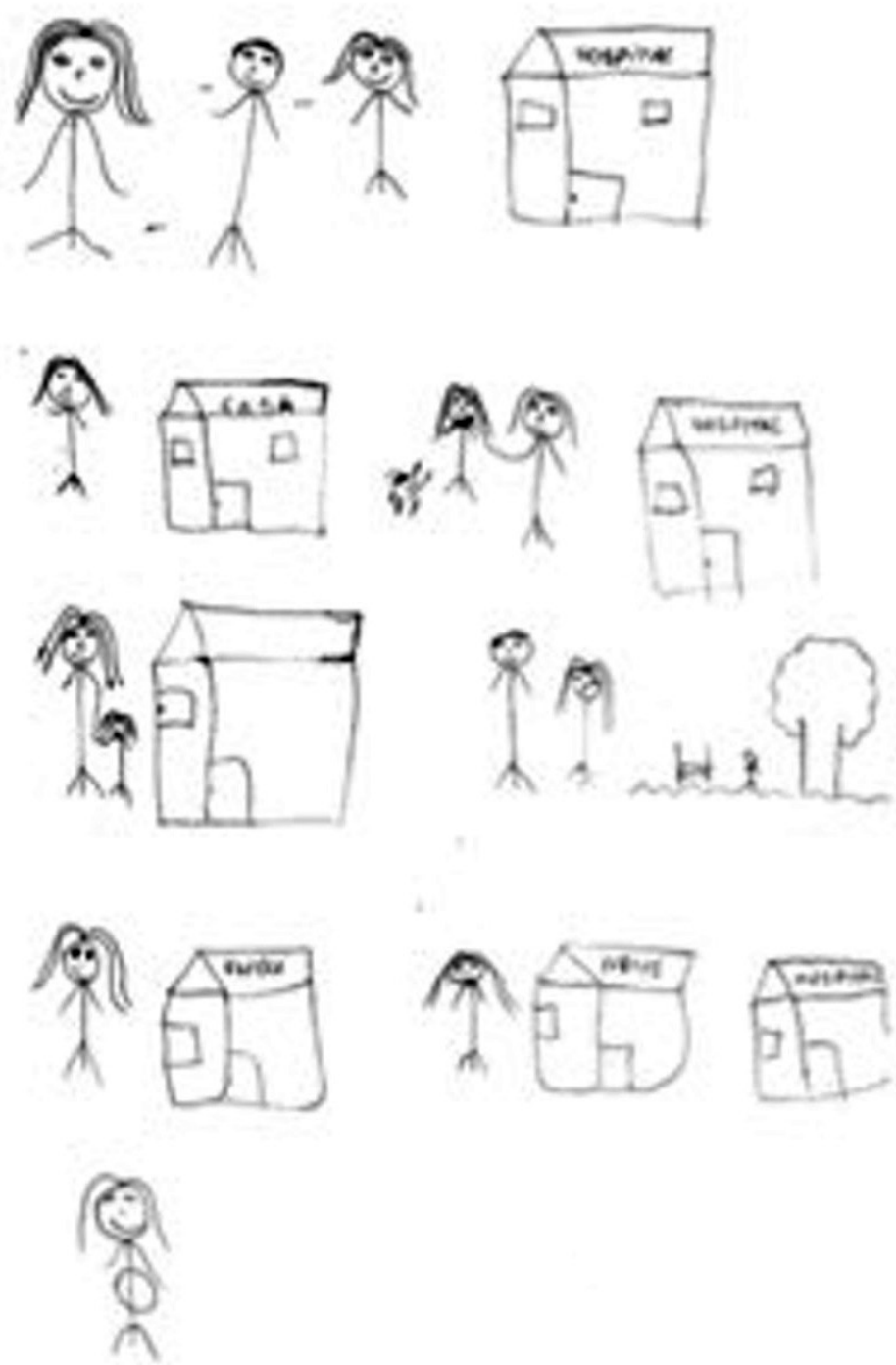
Coisas que Adriana tem para dizer: "só vim conhecer o que era vaidade depois que me casei”.

Adriana, potiguara, 36 anos, era casada e tinha uma filha. Aos 15 anos, mudou-se para Teresina. Teve que largar os estudos cedo para ajudar nas despesas de casa. Demonstrou preocupação com sua família, pois aos 12 anos viu seu único irmão falecer. Por conta disso, foi superprotegida em casa e teve infância e adolescência muito restritivas. No quesito vaidade, só foi conhecer o que era maquiagem após o casamento. Demonstrava ser preocupada com a família, religiosa, vaidosa e se considerava livre. Comentou que a conquista da liberdade era motivo de felicidade, uma vez que teve uma adolescência de muitas restrições. Em se tratando da construção de sua rede assistencial, pontuou que foi desafiante. Foi informada no pré-natal que sua filha iria nascer com uma fenda orofacial. Contudo, não recebeu orientação e se viu perdida quando sua filha nasceu. $\mathrm{O}$ acesso à rede se deu por meio do plano de saúde da sua filha. Não tinha conhecimento do acesso na rede pública (figura 3).

Figura 3. Por trás de Adriana
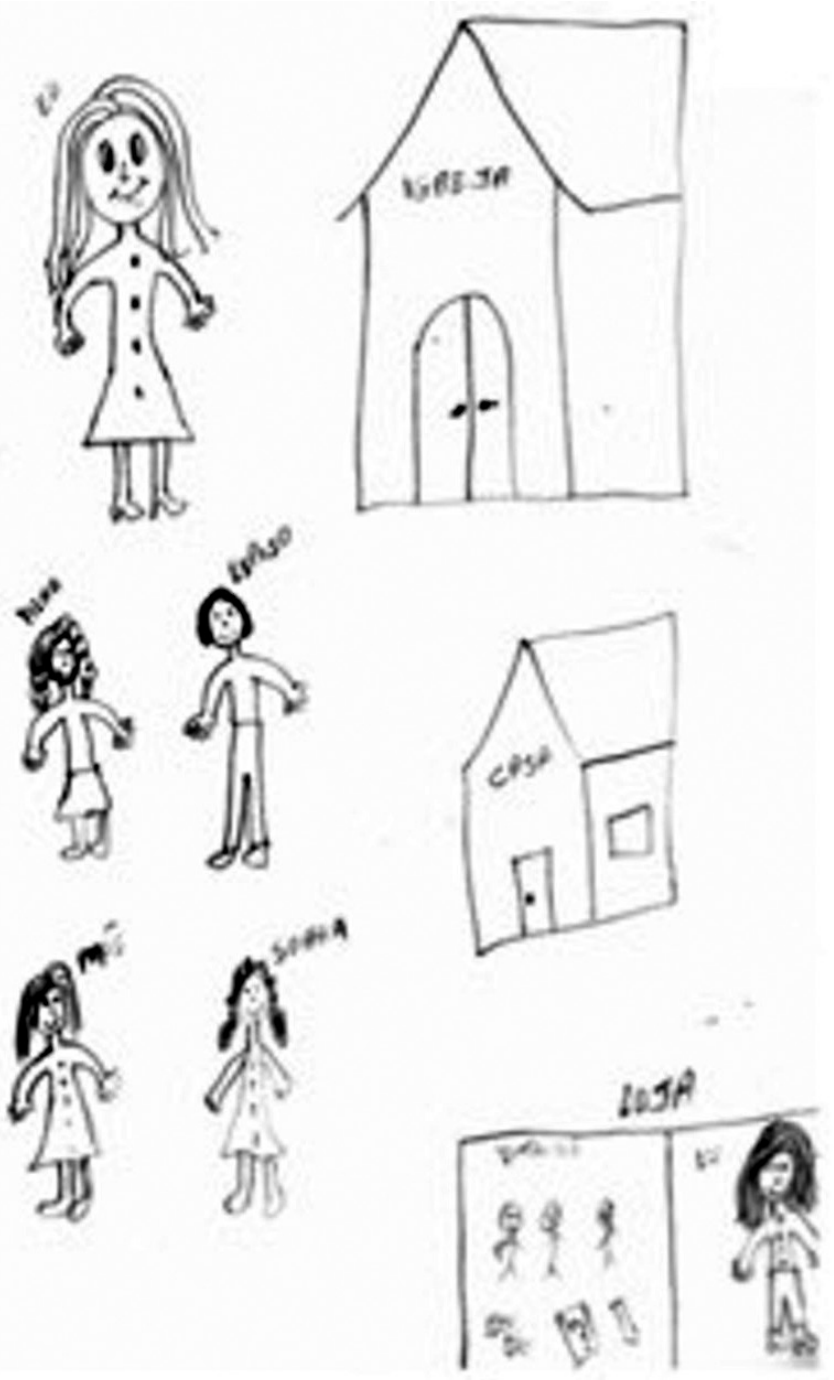
As várias afetações de Edith: "faço tratamento desde o nascimento [...] sou uma pessoa muito feliz por ter saúde".

Edith, teresinense, 19 anos, era solteira e nasceu com fenda orofacial. Sua mãe tomou consciência da sua condição de saúde somente após seu nascimento. Tinha uma irmã que nasceu com a mesma expressão que a sua, mas faleceu com 2 meses de vida. Fazia tratamento desde seu nascimento e era muito grata por sua saúde. Estava terminando o ensino médio em uma escola particular. Em seu tempo livre, ajudava no empreendimento de sua tia. Edith morava com sua mãe. Seus pais se separaram quando ela tinha 14 anos. Apesar disso, os pais de Edith mantiveram contato, e isso a deixava bastante feliz, porque poderia contar com o apoio deles. Edith se sentia fortalecida pela união de sua família e seus amigos. Com isso, não tinha motivos para lamentar; somente, agradecer. Algumas pessoas chegavam a mencionar para ela que nunca a viam triste. Certo dia, perguntou à sua mãe quantas cirurgias já tinha feito, e ela respondeu que "tinha perdido as contas". Relatou que não sentia medo diante dos procedimentos cirúrgicos que precisava fazer. Percebia o quanto melhoravam sua fala e sua aparência (figura 4).

Figura 4. Autorretrato de Edith

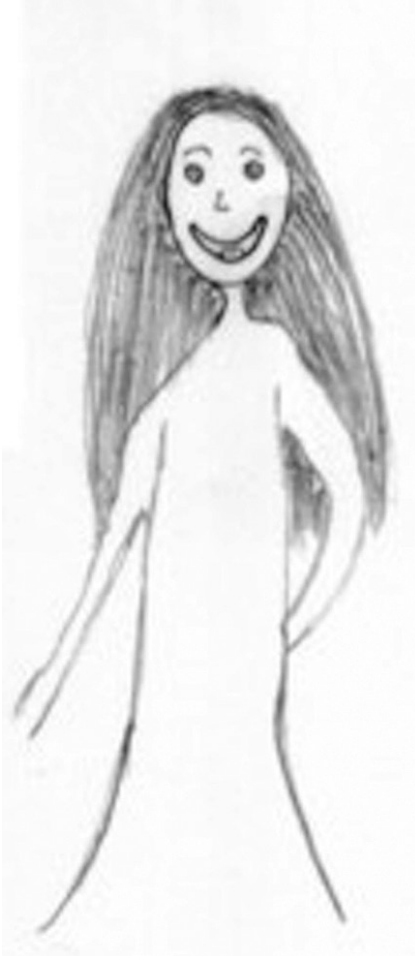

Ao analisar as narrativas dessas mulheres, identificaram-se quatro unidades de significado: Ser-fissurado?; Rede de cuidados; Fluxos assistenciais em saúde bucal para pessoas com fenda orofacial e suas expressões; e Percepção sobre os serviços de saúde (figura 5). 
Figura 5. Unidades de sentido relacionadas à rede de cuidados de pessoas com fenda orofacial e suas expressões

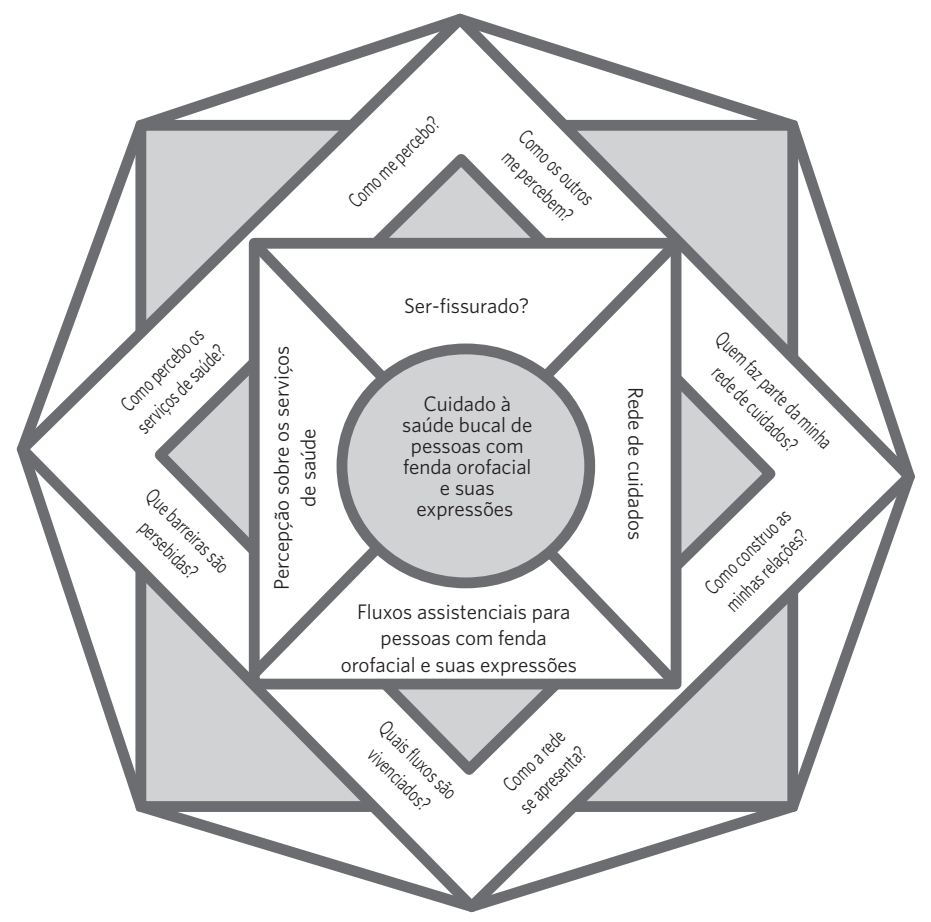

a) Ser-fissurado?

Alguns sujeitos percebem a fenda orofacial como um problema de constituição física, que pode envolver lábio, gengiva, palato e comprometer as funções mastigatórias, a fonação e o alinhamento dentário (estética). Trata-se de um tipo de má-formação não sindrômica, comum na região craniofacial, e que acarreta diversos transtornos, entre eles, os sintomas depressivos ${ }^{20,21}$.

Quando questionados, os participantes da pesquisa relataram não se sentirem satisfeitos com o termo 'fissura', utilizado para tratar desse problema. Uma delas mencionou que: "fissura só me lembra de cachorro" (Frida). Diante dessa narrativa, é importante refletir acerca da terminologia mais adequada e da forma de abordar os sujeitos. Não atentar para isso poderá contribuir para a reprodução do preconceito, reforçar o estigma que atravessa as expressões da fenda orofacial e interferir na qualidade de vida de cada uma dessas pessoas ${ }^{22}$.
Historicamente, o termo utilizado para esses casos era 'lábio leporino', e foi atribuído às pessoas que sofriam com defeito congênito caracterizado pela fusão do processo nasal mediano com o processo maxilar (fissura ou fenda labial). A falha na fusão das prateleiras palatinas resultava em fenda palatina ${ }^{23}$. A fenda na área labial era similar, morfologicamente, com a região labial apresentada pelos mamíferos lagomorfos da família Leporiadae, geralmente conhecidos como lebres.

Para o Comitê Federal de Terminologia Anatômica (FCAT) e a Federação Internacional das Associações de Anatomistas (IFAA), os termos mais apropriados são fenda labial, fenda palatina ou fenda labiopalatina/orofacial, pois descrevem concretamente essa falha de desenvolvimento e evita uma comparação morfológica que, de certa forma, torna-se desdenhosa e não obedece a uma linguagem médica e científica apropriada ${ }^{24}$.

Esse tipo de fenda pode ser percebido ainda durante a gestação, por meio do exame 
de ultrassonografia morfológica. Contudo, o nível de comprometimento funcional e estético da fenda só é possível detectar após o nascimento ${ }^{25}$. Isso significa dizer que, desde cedo, a gestante poderá se apropriar dessa expressão e dos principais cuidados que deve compartilhar com os seus filhos. Além disso, essa informação, ainda durante a gestação, poderá preparar a mãe quanto aos sentimentos e afetações relacionados a essa descoberta.

Quando questionadas sobre as reações diante do diagnóstico, algumas mulheres relataram ansiedade, medo e apreensão: "quando minha mãe me viu, teve reação de susto [...] aceitou, porque tinha solução" (Frida). Isso foi minimizado por meio de consulta aos profissionais, além da rede de apoio, familiares e amigos:

o médico falou para minha mãe, durante o exame, que eu tinha um problema e deveria fazer uma cirurgia [...] mas ela só entendeu o problema quando nasci. (Edith).

Isso também aconteceu com as pessoas que apresentavam a fenda orofacial, na medida em que começavam a se apropriar do seu próprio corpo e se relacionavam com outras pessoas. O olhar do outro sobre aquela expressão era percebido com diferença e estigma: "minha voz era anasalada ao ponto de ninguém entender nada [...] perguntavam se era de outro país ou de outro mundo" (Frida). Goffman ${ }^{26}$ trata do estigma como o produto de um juízo de valor que se atribui a uma pessoa sem levar em consideração as suas qualidades, que pode gerar comportamentos sociais defensivos ou, mesmo, o isolamento social.

Os impactos no convívio social mencionados pelos sujeitos estavam relacionados a problemas com a fonação e a estética. Quanto à comunicação, mencionaram a vergonha e o medo de falar diante da dificuldade de articulação das palavras: "tenho vergonha de falar [...] medo de não conseguir me expressar" (Edith).

Os impactos no convívio social relacionados ao estigma estético acontecem diante da expressão da fenda labial e do achatamento do nariz. Isso pode ser percebido pelos sujeitos no contato com outras pessoas em cada um dos espaços que frequentam: "o povo fala: meu Deus!!! [...] tens aquilo diferente no lábio" (Edith).

Acredita-se que a educação em saúde pode ser um dos mecanismos para minimizar os estigmas sociais relacionados à pessoa com fenda orofacial. Isso pode ser oportunizado em momentos diferentes, na tentativa de estabelecer o contato com as diversas temáticas, as suas expressões e as formas de cuidar. A educação em saúde, enquanto estratégia de promoção da saúde, tem sido caracterizada como um veículo transformador de práticas e comportamentos, capaz de construir mecanismos que possam reduzir os estigmas sociais ${ }^{27}$.

Apesar do estigma, os sujeitos mencionaram buscar estratégias para a sua superação. $\mathrm{O}$ reconhecimento do estado de saúde no âmbito sistêmico esteve muito além da expressão restritiva da fenda orofacial:

não tenho nenhum motivo para chorar [...] as outras pessoas falam que nunca estou triste, só estou sorrindo [...] sou uma pessoa muito feliz por ter saúde. (Edith).

b) Rede de cuidados

Diante das necessidades geradas, foi possível compreender a rede de cuidados construída por cada um dos sujeitos entrevistados. Em cada uma das narrativas, percebeu-se que a rede tem início no âmbito familiar e tem sido o motivo do bem-estar subjetivo: "o que mais me faz feliz, hoje, é saber que meus pais me apoiam em tudo" (Edith).

De fato, os pais têm sido essenciais para compor a rede de cuidados. Após a fase de apropriação da sua saúde e do reconhecimento da falta de recursos para o cuidar-de-si, os sujeitos costumam mobilizar o seu núcleo familiar ${ }^{28}$. Isso perpassa a afetividade e a responsabilização, e é indispensável para operar a transformação mencionada anteriormente sobre a efetivação do cuidado. 
Durante o tratamento, o papel dos pais e responsáveis está relacionado com a continuidade do pós-operatório no âmbito domiciliar, de forma compartilhada com a equipe de saúde. É construído a partir das dificuldades do cotidiano ${ }^{29}$. Isso se estende aos cônjuges, na medida em que se formam novos laços afetivos e amorosos com outros sujeitos: "em relação à saúde, posso contar com duas pessoas: meu esposo e minha mãe" (Frida).

Isso significa dizer que a família, por muitas vezes, sente-se fragilizada diante do quadro clínico vivenciado e também precisa de atenção. Aqui, podem-se mencionar dificuldades nas relações interpessoais, com destaque para a falta de estrutura emocional que alicerça essa rede de apoio. Entre os sentimentos que essa família possa vivenciar e que, possivelmente, podem comprometer o suporte no cuidado, estão: a desesperança, a impotência e o medo. Esses são alguns exemplos de aspectos que merecem atenção.

Neste estudo, algumas adversidades foram entendidas como barreiras para o cuidado. Foram relatadas dificuldades inerentes ao tratamento longo e invasivo da fenda orofacial e ao afastamento da família devido a essa condição: "meu pai só namorou com minha mãe [...] engravidou ela [...] e devido eu ter nascido com a fenda, ele a abandonou" (Frida).

O tratamento da pessoa com fenda orofacial, usualmente, torna-se complexo e longo, pois inclui uma equipe multiprofissional em contatos frequentes, assim como a realização de procedimentos cirúrgicos bastante invasivos aliados à observação da evolução e do processo de cicatrização ${ }^{30}$. Aqui, o vínculo com os profissionais opera em prol do cuidado e possibilita o reconhecimento da situação de saúde, além da tomada de decisões sobre a conduta e a adesão ao plano de tratamento proposto ${ }^{31}$. Isso foi observado em algumas narrativas:

durante as internações, eu achei bom, porque, apesar de ficar no hospital, fui muito bem cuidada. (Frida). o hospital representou boa parte da minha vida até os dias de hoje [...] agradeço muito aos profissionais de lá [...] todo tratamento [...] eu gosto de ir lá, me sinto em casa. (Tarsila).

Esse vínculo com a equipe multiprofissional do hospital, por vezes, foi representado de forma individual por um único profissional: "a doutora faz parte da vida de todo mundo que tem a fenda labiopalatina" (Frida). A centralização do cuidado na figura de um único profissional em um equipamento de saúde em um nível de atenção terciário não foi vista como oportunidade neste estudo. Isso poderá comprometer a unidade da rede. Acredita-se que devem existir profissionais de referência em cada um dos níveis de atenção na tentativa de articular o cuidado mediante as necessidades de saúde dos sujeitos.

c) Fluxos assistenciais em saúde bucal para pessoas com fenda orofacial e suas expressões

A assistência integral à mulher, que inclui o planejamento familiar e o pré-natal, constitui requisito basilar na Estratégia Saúde da Família $(\mathrm{ESF})^{32}$. A gravidez é um período de mudanças físicas e emocionais que as mulheres vivenciam de forma distinta. Essas transformações podem gerar medo, dúvidas, angústias, fantasias ou simplesmente curiosidade de saber o que acontece no interior do seu corpo ${ }^{32}$.

Nesse aspecto, as equipes de Saúde Bucal (eSB) também devem valorizar esse período tão significativo na vida da mulher, incluindo a atenção odontológica no pré-natal. No entanto, é preciso ir além da atenção multiprofissional. É necessário tencionar práticas interdisciplinares e intersetoriais na tentativa de ampliar as possibilidades de cuidado para a saúde da mulher e da criança.

A assistência à saúde da pessoa com fenda orofacial e suas expressões inicia-se antes mesmo do nascimento. É importante que o primeiro contato se dê, ainda, no planejamento familiar e durante o pré-natal, uma vez que existem fatores etiológicos que extrapolam a genética, como a exposição ao álcool, ao 
cigarro, as deficiências nutricionais e a exposição a defensivos agrícolas ${ }^{23}$. Durante as consultas de pré-natal, por exemplo, deverão ser feitas investigações sobre os fatores de risco e fatores protetivos relacionados a essa expressão, a fim de reconhecer as necessidades imediatas de cuidado e de estabelecer uma conduta de contato, articulação e a integração com os serviços de referências. Esse é um dos pré-requisitos de constituição da rede ${ }^{33}$. A falta de informação nesse período pode ocasionar alguns problemas, que incluem o desconhecimento da rede assistencial: "quando soube, durante a gestação, o médico não me informou nada sobre o tratamento de fenda [...] não sabia como conseguir uma consulta pelo SUS" (Adriana).

Uma vez iniciado o tratamento, as consultas devem acontecer periodicamente, pois as expressões da fenda orofacial acompanham as fases de desenvolvimento e crescimento da criança, sendo necessárias intervenções em períodos de tempo que só podem ser determinados mediante análise: "éfeito acompanhamento com a doutora em relação à dentição, pois [...] a pessoa que nasce com a fenda não tem os dentes alinhados" (Adriana).

A proposta de rede vivenciada no SUS tem a atenção básica $(\mathrm{AB})$ como coordenadora e reguladora do cuidado ${ }^{33}$. As consultas para os equipamentos de atenção secundária e terciária devem ser reguladas pelas UBS, compondo, assim, o sistema de referência e contrarreferência. Neste estudo, observou-se que os profissionais da $\mathrm{AB}$ não estavam preparados para orientar o usuário na rede:

na UBS, pedi para marcar para o hospital, mas não colocaram o nome do profissional, e voltei [...] na UBS, de volta, disseram que não sabiam fazer [...] liguei para o hospital, e a atendente deu as orientações para a funcionária do Same [Serviço de Arquivamento Médico e Estatística]. (Adriana).

A falta de informações sobre a organização e o funcionamento dos serviços e o despreparo da equipe do Same, nesse caso, constituem as barreiras funcionais.
A dificuldade no acesso às consultas especializadas de serviços públicos também foi relatada pelas participantes desta pesquisa:

nunca recorri à UBS porque demora e tem que acordar de madrugada [...] vou ao plano de saúde [...] em três dias liberam a cirurgia. (Adriana).

hoje, para tudo que for fazer [...] você marca no posto de saúde e agenda a consulta [...] uma luta. (Frida).

O cuidado à saúde não se materializa somente com o acesso ao procedimento. A falta de informação e o despreparo dos cuidadores antes da realização dos procedimentos poderão ocasionar desconforto e interferir no vínculo com a equipe de saúde ${ }^{31}$. É indispensável incorporar a família em todas as etapas. Isso inclui a tomada de decisões quanto aos procedimentos que serão oportunizados à pessoa com fenda, as orientações no pré e no pós-operatório.

As crianças submetidas aos procedimentos cirúrgicos, quilorrafia e palatorrafia reconstrutoras da fenda labial e da fenda palatina, respectivamente, devem receber alta hospitalar quando seus cuidadores estiverem aptos aos cuidados inerentes à cirurgia ${ }^{\mathbf{2 4}, 29}$. Essas são as primeiras cirurgias plásticas reparadoras executadas durante o longo e complexo tratamento das pessoas com fenda orofacial.

Para crianças que nascem com a fenda, a cirurgia é um desafio não só estético, mas, principalmente, funcional. Os cuidados incluem a preparação e a atenção na consistência dos alimentos, utensílios utilizados para a administração da alimentação, técnica de limpeza da ferida operatória, realização da higiene oral, sinais e sintomas de dor, analgésicos a serem utilizados em cada um dos casos e reconhecimento de sangramento atípico ${ }^{31}$. Algumas dessas complicações foram relatadas: "tudo que eu comia, vomitava e derramava muito sangue [...] voltei para casa depois de muito tempo no hospital" (Tarsila). 
A atuação multiprofissional e a conduta interdisciplinar também contribuem para construir o cuidado à saúde das pessoas com fenda orofacial. Entre os profissionais, tem-se o Cirurgião-Dentista (CD), que tem como desafio a promoção de saúde, a prevenção de agravos, o diagnóstico e o tratamento da fenda orofacial, como a restauração de dentes cariados, substituição de dentes ausentes por meio de reabilitações protéticas e ortodônticas, entre outros ${ }^{34}$. Isso tudo sem perder de vista as necessidades de saúde que se somam, como o acompanhamento psicológico, fonoaudiólogo e fisioterapêutico, que estão associados ao cuidado em saúde de forma mais abrangente.

No Brasil, não há uma legislação específica sobre a composição da equipe multidisciplinar ou um modelo organizacional que deve compor a assistência de saúde à pessoa com fenda orofacial. No entanto, estabelece as normas para hospitais credenciados para realização de procedimentos integrados de reabilitação estético-funcional para pessoas com fenda orofacial no SUS ${ }^{35}$. Isso ratifica a necessidade de se pensar em bases normativas que assegurem a composição de uma equipe mínima para o seguimento do cuidado de pessoas com fenda orofacial.

d) Percepção sobre os serviços de saúde No que diz respeito à percepção sobre os serviços de saúde, foram apresentadas outras dificuldades quanto ao acesso:

o acesso à doutora é complicado [...] tive que andar bastante para conseguir [...] tive que pagar para poder falar com ela pela primeira vez e conseguir chegar ao tratamento no hospital. (Adriana).

$\mathrm{O}$ acesso, enquanto atributo da atenção primária à saúde, implica contato e utilização dos serviços de saúde pelos usuários ${ }^{36}$. Neste estudo, percebeu-se que existem diversas barreiras, como a intensa burocratização. Isso resulta em um elevado tempo de espera para as consultas e os exames. Nesse caso, os serviços de saúde parecem construir impedimentos para a construção de uma rede eficiente e resolutiva.
A identificação dos limites do acesso foi observada desde $\mathrm{AB}$ até os serviços de média e alta complexidade. Entende-se que a $\mathrm{AB}$, enquanto porta de entrada, deve disparar processos que mobilizem serviços e setores em prol do cuidado. Nesse sentido, devem-se aglutinar recursos para que isso se concretize.

Em outra fase, o acolhimento se apresentou como recurso para a construção de vínculos. Alguns autores mencionam que o acolhimento, quando feito por uma equipe multiprofissional, tem como finalidade manter a escuta qualificada, delimitar de forma participativa os encaminhamentos oportunos e necessários, assim como minimizar as dificuldades inerentes à marcação de consultas e ao acesso ao tratamento nos níveis de atenção especializada e de alta complexidade ${ }^{37}$. Esse deve ser um investimento a ser vivenciado por toda a equipe de saúde, e as interferências diante desse processo devem ser minimizadas ou superadas.

Com relação ao seguimento do tratamento, também foi citada a falta de cobertura de procedimentos de média e alta complexidade, como o acesso ao enxerto ósseo e gengival e a implantes unitários:

o dentista falou que tinha que pagar [o material, tendo em vista que aquele disponibilizado no serviço público era de qualidade inferior] [...] e ainda demorou uns dois meses para liberar [o procedimento] pelo SUS. (Edith).

$\mathrm{O}$ acesso a procedimentos integrados para reabilitação estético-funcional para pessoas com má-formação labiopalatal está amparado legalmente pela Portaria de $\mathrm{n}^{\circ} 718$ desde dezembro de $2010^{35}$. Entretanto, os procedimentos de alta complexidade, como implantes dentários, não foram incluídos como procedimento de reabilitação estético-funcional. Sobre esse acesso, a nota técnica de $\mathrm{n}^{\circ} 23$, de 20 de junho de 2017, previu mudanças a partir do ano de 2018 na composição dos repasses efetuados pelo Fundo Nacional de Saúde, revisando valores de procedimentos ofertados e incluindo a reabilitação com implantodontia e ortodontia pelo SUS ${ }^{\mathbf{3 8}}$. 
Quanto à qualidade do material, entende-se que se trata de uma demanda relacionada à aquisição e ao processo licitatório. Nesse caso, é importante compor uma equipe técnica que seja capaz de descrever a relação dos materiais ou serviços, com suas especificações técnicas apropriadas, além de estabelecer prazos de entrega, condições de recebimento, entre outros. Cabe à equipe responsável por essa atividade acompanhar a compra e o recebimento de cada um dos itens na tentativa de checar se todos os aspectos foram cumpridos.

Vale ressaltar que as falhas nesse processo não justificam a solicitação de materiais e serviços particulares, como se percebe na narrativa anterior. É preciso que as informações sobre a qualidade do material cheguem ao gestor e, assim, possam ser desenhadas outras formas de superar o problema.

No que diz respeito aos cuidados pré e pós-operatório, outro componente interpretativo presente neste estudo, percebeu-se que há despreparo da equipe de saúde e dificuldade de socialização das informações entre os profissionais, clientes e cuidadores: "seria bom que os profissionais do posto de saúde fossem mais informados sobre a fenda [...] eles não sabem orientar" (Adriana).

O cuidado de pessoas com fenda orofacial e suas expressões exige capacitação técnica adequada, que passa pelo conhecimento de especialidades como a cirurgia buco-maxilo-facial, ortodontia e a implantodontia, por exemplo ${ }^{35}$. Isso está relacionado com forte investimento de formação e desenvolvimento profissional.

Aliado a isso, o cuidado exige suporte individual e familiar contínuo. A promoção de saúde e a capacitação dos cuidadores referentes aos aspectos pré e pós-operatórios contribuem para amenizar a sua ansiedade, já que, geralmente, enfrentam níveis elevados de estresse físico e psicológico, além de reduzirem as possíveis complicações pós-operatórias ${ }^{30}$. Neste estudo, algumas situações foram desencadeadoras do nervosismo e da ansiedade, colocando em debate o adequado suporte que deveria ser compartilhado: queria que os médicos explicassem melhor sobre 0 aparelho [...] após a colocação, minha filha vomitava muito [...] fiquei muito nervosa no banheiro do hospital. (Adriana).

Em outras situações, algumas mulheres perceberam diferença no cuidado à saúde entre o serviço público e o privado:

vi uma criança como a minha, que fez a cirurgia e não precisou de pontos [...] fez particular [...] saiu no mesmo dia [...] quem faz pelo SUS é pontilhado e sai depois [...] é de qualquer jeito, mas resolve. (Frida).

Alguns autores mencionam que a prestação de serviço público ainda mantém foco na oferta desse serviço, deixando de se preocupar com a qualidade ${ }^{39}$. A qualidade dos serviços pode ser percebida por meio de componentes de tangíveis e intangíveis. A tangibilidade do serviço consiste naquilo que o usuário consegue perceber e sentir, por exemplo, a aparência física do local ${ }^{39}$. Os componentes intangíveis seriam as características inerentes ao vínculo com os profissionais de saúde, como a humanização do atendimento, sendo, portanto, diretamente ligados ao relacionamento com a equipe multiprofissional e o paciente. Diante disso, é possível ressaltar que podem existir diferenças na prestação de serviços. Contudo, é importante investir em componentes diversos, oferecer alternativas para a decisão conjunta entre os profissionais e clientes, bem como na educação em saúde e comunicação.

Aliado a isso, o acesso aos serviços, públicos ou privados, não assegura o cuidado ${ }^{40}$. A oferta de serviços, tendo em vista o acesso, é um quesito dentro de uma perspectiva multidimensional. O cuidado deve estar centrado na pessoa, considerando a experiência de viver, as suas relações, o cenário e o contexto. As tecnologias no âmbito dos serviços de saúde devem ser acionadas a partir das suas necessidades e demandas na intenção de se construir o plano de cuidados mais apropriado para o caso. 


\section{Considerações finais}

Conclui-se que há uma rede plural de cuidado à saúde bucal construída com elementos formais e informais, bem como uma diversidade de caminhos percorridos no acesso aos serviços. Isso marcou momentos e memórias nas histórias de vida das pessoas com fenda orofacial e suas expressões e contribuiu para a construção de uma identidade singular.

Em Teresina, Piauí, a assistência à saúde bucal está centralizada em único serviço de média e alta complexidade. Há uma rede fragmentada quanto ao cuidado à saúde bucal, com falhas na comunicação, articulação e integração dos serviços, pouco envolvimento e apropriação dos casos pelas equipes de atenção básica, com importantes repercussões dos estigmas sociais sobre o paciente. Isso fragiliza a construção de uma rede e interfere na garantia da integralidade do cuidado.

Estratégias para o aprimoramento das relações, bem como articulação e integração entre os serviços devem ser desenvolvidas na tentativa de superar esses problemas. Acredita-se que o esforço deve ser compartilhado entre os gestores, profissionais de saúde e clientes e que não se constrói uma rede sustentável sem participação, comunicação e humanização.

\section{Colaboradores}

Os autores deste artigo, Ramos PFC (00000002-8188-3559)* e Tajra FS (0000-00017236-5541)*, contribuíram igualmente para a elaboração do manuscrito.

\section{Referências}

1. Assis MAA, Nascimento MAA, Franco TB, et al., organizadores. Produção do cuidado no Programa Saúde da Família: olhares analisadores em diferentes cenários. Salvador: EDUFBA; 2010.

2. Kleba ME, Wendausen A. Empoderamento: processo de fortalecimento dos sujeitos nos espaços de participação social e democratização política. Saúde Soc. 2009; 18(4):733-743.
3. Mendes EV. As redes de atenção à saúde. Brasília: Organização Pan-Americana da Saúde; 2011. [acesso em 2020 mar 7]. Disponível em: http://bvsms.saude.gov. br/bvs/publicacoes/redes_de_atencao_saude.pdf.

4. Brasil. Ministério da Saúde. Portaria no 4279, de 30 de dezembro de 2010. Estabelece diretrizes para a organização da rede de atenção à saúde no âmbito do Sistema Único de Saúde (SUS). Diário Oficial da
${ }^{*}$ Orcid (Open Researcher and Contributor ID). 
União [internet]. 30 Dez 2010. [acesso em 2020 mar 7]. Disponível em: http://bvsms.saude.gov.br/bvs/ saudelegis/gm/2010/prt4279_30_12_2010.html.

5. Brasil. Decreto $n^{0} 7508$, de 28 de junho de 2011. Regulamenta a Lei $n^{\circ}$ 8080, de 19 de setembro de 1990, para dispor sobre a organização do Sistema Único de Saúde (SUS), o planejamento da saúde, a assistência à saúde e a articulação Inter federativa, e dá outras providências. Diário Oficial União [internet]. 28 Jun 2011. [acesso em 2020 mar 7]. Disponível em: http:// www.planalto.gov.br/ccivil_03/_Ato2011-2014/2011/ Decreto/D7508.htm.

6. Moysés ST, Kriger L, Moysés SJ, organizadores. Saúde bucal das famílias: trabalhando com evidências. São Paulo: Artes Médicas; 2008.

7. Pucca Jr GA. A política nacional de saúde bucal como demanda social. Ciênc. Saúde Colet. 2006; 11(1):243246.

8. Costa JFR, Chagas LD, Silvestre RM. A política nacional de saúde bucal do Brasil: registro de uma conquista histórica. Brasília, DF: Organização Pan-Americana da Saúde; 2006.

9. Santos Neto ET, Alves KCG, Zorzal M, et al. Políticas de saúde materna no Brasil: os nexos com indicadores de saúde materno-infantil. Saúde Soc., 2008; 17(2):107-119.

10. Brasil. Ministério da Saúde, Secretaria de Atenção à saúde, Departamento de Ações programáticas estratégicas. Portaria n ${ }^{\circ}$ 1.459, 24 de junho de 2011. Institui, no âmbito do Sistema Único de Saúde, a Rede Cegonha. Diário Oficial da União [internet]. 24 Jun 2011. [acesso em 2020 mar 7]. Disponível em: http://bvsms.saude.gov.br/bvs/saudelegis/gm/2011/ prt1459_24_06_2011.html.

11. Brasil. Ministério da Saúde. Portaria n ${ }^{\circ} 793$, de 24 de abril de 2012. Institui a Rede de Cuidados à Pessoa com Deficiência no âmbito do Sistema Único de Saúde. Diário Oficial da União [internet]. 24 Abr 2012. [acesso em 2020 mar 7]. Disponível em: http://bvsms.saude.gov.br/bvs/saudelegis/gm/2012/ prt0793_24_04_2012.html.

12. Dubow C, Garcia EL, Krug SBF. Percepções sobre a Rede de Cuidados à Pessoa com Deficiência em uma Região de Saúde. Saúde debate. 2018; 42(117):455-467.

13. Brasil. Ministério da Saúde. Portaria SAS/MS nº 62 , de 19 de abril de 1994. Normaliza cadastramento de hospitais que realizem procedimentos integrados para reabilitação estético-funcional dos portadores de má-formação lábio-palatal para o Sistema Único de Saúde. Diário Oficial da União [internet]. 19 Abr 1994. [acesso em 2020 mar 7]. Disponível em: http://bvsms.saude.gov.br/bvs/saudelegis/sas/1994/ prt0062_19_04_1994.html.

14. Almeida AMFL, Chaves SCL, Santos CML, et al. Atenção à pessoa com fissura labiopalatina: proposta de modelização para avaliação de centros especializados, no Brasil. Saúde debate. 2017; 41(esp):156-166.

15. Brasil. Ministério da Saúde. Relatório de Gestão 2015. Brasília, DF: Ministério da Saúde; 2016.

16. Deslandes SF, Gomes RA. A pesquisa qualitativa nos serviços de saúde: notas teóricas. In: Bosi MLM, Mercado-Martinez FJ, organizadores. Pesquisa qualitativa de serviços de saúde. Petrópolis: Vozes; 2004.

17. Spindola T, Santos RS. Trabalhando com a história de vida: percalços de uma pesquisa(dora?). Rev. Esc. Enferm USP. 2003; 37(2):119-26.

18. Ricoeur P. Teoria da Interpretação. O discurso e o excesso de significação. Lisboa: Edições 70; 1976.

19. Terra MG, Gonçalves LHT, Santos EKA, et al. Fenomenologia-hermenêutica de Paul Ricoeur como referencial metodológico numa pesquisa de ensino em enfermagem. Acta Paul. Enferm. 2009; 22(1):93-99.

20. Martelli DRB, Machado RA, Swerts MSO, et al. Fissuras lábio palatinas não sindrômicas: relação entre o sexo e a extensão clínica. Braz. j. otorhinolaryngol. 2012; 78(5):116-120. 
21. Lima LS, Ribeiro GS, Aquino SN, et al. Prevalência de sintomas depressivos em pacientes com fissuras labiopalatinas. Braz. j. otorhinolaryngol. 2015; 81(2):177183.

22. Raposo-do-Amaral CE, Kuczynski E, Alonso N. Qualidade de vida de crianças com fissura labiopalatina: análise crítica dos instrumentos de mensuração. Rev. Bras. Cir. Plást. 2011; 26(4):639-644.

23. Neville BW, Damm DD, Allen CM, et al. Defeitos do desenvolvimento da região maxilofacial e oral. In: Neville BW, Damm DD, Allem CM, et al. Patologia Oral e Maxilofacial. 2. ed. Rio de Janeiro: Guanabara Koogan; 2011.

24. Ellis III E. Tratamento de pacientes com fenda orofaciais. In: Hupp JR, Ellis III E, Tucker MR. Cirurgia oral e maxilofacial contemporânea. 5. ed. Rio de Janeiro: Elsevier; 2009. p. 575-94.

25. Vanz AP, Ritter NR. Escutando as mães de portadores de fissuras orais. Rev. Esc. Enferm. 2011; 45(3):596602.

26. Goffman E. Estigma: notas sobre a manipulação da identidade deteriorada. Tradução de Mathias Lambert. Rio de Janeiro: LTC; 1988.

27. Munguba MCS, Vieira ACVC, Porto CMV. Da invisibilidade à participação social: promoção da saúde em pessoas com deficiência. Rev. Bras. Promoç. Saúde. $2015 ; 28(4): 463-466$.

28. Tajra FS, Pontes RJS, Carvalho FHC. The possible meanings of care: self-care and care-for-the-other. Invest. educ. Enferm. 2017; 35(2):199-209.

29. Melo EMOP, Ferreira PL, Lima RAG, et al. Envolvimento dos pais nos cuidados de saúde de crianças hospitalizadas. Rev. Latino-Am. Enfermagem. 2014; 22(3):432-9.

30. Trettene AS, Razera APR, Maximiano TO, et al. Dúvidas de cuidadores de crianças com fissura labiopalatina sobre os cuidados pós-operatórios de queilo- plastia e palatoplastia. Rev. Esc. Enferm. USP. 2014; 48(6):993-8.

31. Nascimento MAA, Santos SCMC, Assis MMA, et al. Vínculo e responsabilização na construção da produção do cuidado no programa saúde da família. In: Assis MMA, Nascimento MAA, Franco TB, et al., organizadores. Produção do cuidado no Programa Saúde da Família: olhares analisadores em diferentes cenários [internet]. Salvador: EDUFBA; 2010. p. 113-25. [acesso em 2020 jan 20]. Disponível em: http://books. scielo.org/id/xjcw9.

32. Brasil. Ministério da Saúde. Assistência Pré-natal: Manual técnico/equipe de elaboração. 3. ed. Brasília, DF: Ministério da Saúde; 2000.

33. Conselho Nacional de Secretários de Saúde. A Atenção Primária e as Redes de Atenção à Saúde. Brasília, DF: Conass; 2015.

34. Lorenzzoni D, Carcereri DL, Locks A. The importance of multi-professional, interdisciplinary care in rehabilitation and health promotion directed at patients with cleft lip/palate Rev. Odonto Ciênc. 2010; 25(2):198-203.

35. Brasil. Ministério da Saúde. Portaria n ${ }^{\circ} 718$, de 20 de dezembro de 2010. Estabelece as normas para o cadastramento de Hospitais que realizem Procedimentos integrados para reabilitação estético-funcional dos portadores de má-formação lábio-palatal para o Sistema Único de Saúde. Diário Oficial da União [internet]. 20 Dez 2010. [acesso em 2020 mar 7]. Disponível em: http://bvsms.saude.gov.br/bvs/saudelegis/ sas/2010/prt0718_20_12_2010.html.

36. Starfield B. Atenção primária: equilíbrio entre necessidades de saúde, serviços e tecnologia Brasília, DF: UNESCO; Ministério da Saúde; 2002.

37. Reis RS, Coimbra LC, Silva AAM, et al. Acesso e utilização dos serviços na Estratégia Saúde da Família na perspectiva dos gestores, profissionais e usuários. Ciênc. Saúde Colet. 2013; 18(11):3321-31. 
38. Brasil. Ministério da Saúde. Nota Técnica $n^{\circ} 23$, de 20 de junho de 2017. Informações sobre os procedimentos de implantodontia no SUS. 2017. [acesso em 2020 jan 20]. Disponível em: http://189.28.128.100/ dab/docs/portaldab/documentos/nt_cgsb_23_2017. pdf.

39. Fadel MAV, Regis Filho GI. Percepção da qualidade em serviços públicos de saúde: um estudo de caso. Rev. Adm. Púb [internet]. 2009 [acesso em 2020 jan
20]; 43(1). Disponível em: http://bibliotecadigital. fgv.br/ojs/index.php/rap/article/view/6677.

40. Franco TB, Hubner LCM. Clínica, cuidado e subjetividade: afinal, de que cuidado estamos falando? Saúde debate. 2019; 43(esp6):93-103.

Recebido em 23/04/2019

Aprovado em 07/02/2020

Conflito de interesses: inexistente

Suporte financeiro: não houve 